\title{
Effects of Pressure Maintenance and Strain Maintenance during Compression on Subsequent Dimensional Stability and Density after Relaxation of Blocks of Chopped Corn Straw
}

Honglei Jia, ${ }^{\mathrm{a}, \mathrm{b}}$ Tianyou Chen, ${ }^{\mathrm{a}, \mathrm{b}}$ Shengwei Zhang, ${ }^{\mathrm{a}, \mathrm{b}}$ Xumin Sun, ${ }^{\mathrm{a}, \mathrm{b}}$ and Hongfang Yuan ${ }^{\mathrm{a}, \mathrm{b}, *}$

\begin{abstract}
Chopped corn straw is a viscoelastic material that can rebound after compression. Pressure maintenance and strain maintenance are two key processes that enhance the dimensional stability of post-compression straw blocks. To study the effects of stabilization processes on the dimensions of post-compression straw blocks, the authors comparatively explored the relationships of strain and stress with time during constantspeed compression (CC), constant-speed compression followed by strain maintenance (CCS), constant-speed compression followed by pressure maintenance (CCP), and constant-speed compression, pressure maintenance followed by strain maintenance (CCPS), and uncovered the reasons for these relationships. The Burgers constitutive model fit well to the data during the pressure maintenance stage $\left(R^{2}>0.990\right)$, and the effects of pressure maintenance on strain and dimensional stability of post-compression straw blocks were investigated. The Wiechert model B $\left(R^{2}>0.990\right)$ was the constitutive model that best represented the strain maintenance stage. Additionally, the effects of strain maintenance during CCS and CCPS on relaxation rate and dimensional stability of postcompression straw were compared. The relaxation density of postcompression straw blocks was compared among different stabilization processes. The relaxation density of post-compression straw blocks was the largest after CCPS, followed by CCS and CCP.
\end{abstract}

Keywords: Chopped corn straw; Pressure maintenance; Strain maintenance; Dimensional stability coefficient; Relaxation density

Contact information: a: School of Biological and Agricultural Engineering, Jilin University, Changchun 130022, China; b: Key Laboratory of Bionic Engineering, Ministry of Education, Jilin University, Changchun 130022, China; *Corresponding author: yhf1984828@163.com

\section{INTRODUCTION}

Crop straw is critical renewable biomass resources, with an annual yield of over 2 billion tons in the world and 0.9 billion tons in China (Wang et al. 2016), of which onethird comes from corn straw (Yuan et al. 2011). Corn straw is mainly composed of cellulose, hemicelluloses, and lignin, and can be used as fuels, feeds, fertilizers, base materials, and raw materials (Zhang et al. 2016; Aguayo et al. 2017). However, the reclamation and utilization rates of corn straw is discouraged due to loosening, low density, and high seasonality (Chen et al. 2013). Thus, chopping, compressed compaction, and bundling are needed to lower the transportation and storage costs and to raise usage rates (Adapa et al. 2011; Miao et al. 2015). In addition to returning straw to fields, other procedures of utilization include pick up, cutting, densifying, baling, and reclamation (Hou 2013). 
Compressed compaction is a key procedure of straw reclamation. Because corn straw is a viscoelastic material (Ma et al. 2016, 2017), stabilization processes (e.g., pressure maintenance or strain maintenance) are needed to diminish the rebounding of postcompression straw blocks, increase dimensional stability, and thereby enhance the compression effect. The concrete process flow is loaded compression, pressure (strain) maintenance, and completion of compression. Four processes can be used in straw compression, including constant-speed compression (CC) (Jha et al. 2008; Liu et al. 2017; Ma et al. 2017), constant-speed compression followed by strain maintenance (CCS) (Adapa et al. 2009; Nona et al. 2014; Guo et al. 2016), constant-speed compression followed by pressure maintenance (CCP) (Mani et al. 2006; Li 2011; Wongsiriamnuay and Tippayawong 2015), and constant-speed compression, pressure maintenance followed by strain maintenance (CCPS). The former three processes have been extensively applied, but the use of the fourth process has not been found in the existing research.

Pressure maintenance aims to maintain the maximum compression stress constant, while the strain is time-variable ( $\mathrm{Li}$ 2011). Since the straw at this stage is still under pressure maintenance in moulds, strain has been observed to increase with the pressure maintenance time, but the increasing rate is low ( $\mathrm{Li} \mathrm{2011).} \mathrm{Thus,} \mathrm{the} \mathrm{strain} \mathrm{of} \mathrm{the}$ compressed straw blocks is one-dimensional (at the compression direction). Creep refers to a process in which loading is unchanged and strain varies with time. During practical tests, load is applied randomly to a certain extent and then maintained constant for creep. Thus, the compressed pressure maintenance stage of straw can be considered postcompression creep behavior and called pressure maintenance creep (Yang 2010; Li 2011). L (2011) found that compression strain of corn straw further increased at the pressure maintenance creep stage, and that strain stabilized with the prolonging of pressure maintenance time. Li et al. (2019) expressed this as "pressure maintenance relaxation." However, pressure maintenance and strain maintenance are different conceptions and different technological processes. The dimensional stability coefficient after days of placement was studied after post-compression biomass departed from the compression cavity, and the pressure maintenance time significantly affected the dimensional stability of post-compression straw blocks. Wongsiriamnuay and Tippayawong (2015) found that the expansion coefficient of corn straw blocks after $5 \mathrm{~d}$ of relaxation first increased and then decreased within 150 to $250 \mathrm{MPa}$. With straw carbon as the raw material, Chen et al. (2016) studied the effects of pressure maintenance on dimensional stability at $3 \mathrm{~d}$ after removal from the cavity and found that the dimensional stability coefficient first increased, then decreased slightly, and finally stabilized with prolonged pressure maintenance time.

Strain maintenance is the process in which stress of post-compression straw blocks attenuates with time while the strain is unchanged, which is essentially stress relaxation (Ma et al.2016). Thus, at the strain maintenance stage, the sizes of the compressed straw blocks did not change, so it did not concern the change of strain. The existing research focuses on constitutive models, relaxation process, and rate of relaxation. The stress relaxation and essence of post-compression straw blocks can be described and explained with the help of mechanical elements (Mohsenin and Zaske 1976; Chen et al. 2013; Herak et al. 2015). Mani et al. (2004) and Shaw (2008) characterized the stress relaxation of wheat oats and other biomass straw under constant water contents using Peleg's linear models. Hu et al. (2009) compared the stress relaxation of corn, cotton, wheat, and rice straw. Myhan and Jachimczyk (2015) elaborated the stress relaxation of compressed straw layers based on a Baader model and regarded the compressed straw as multiple layers of chopped straw, in which each layer is viscous, elastic, plastic, and impacted by both 
outward loading and internal forces. Chen et al. (2013) and Guo et al. (2016) separated the stress relaxation of wheat straw into two stages, where first $80 \%$ to $85 \%$ of total stress is rapidly released within a short time, and then stress slowly relaxes until equalization in the second stage. Talebi et al. (2011) found that the relaxation rate of hays is positively correlated with both pressure and water content. The maximum pressure was 5.88 to 14.88 $\mathrm{MPa}$, the water content ranged from $6.38 \%$ to $18.94 \%$ w.b., and the relaxation rates of high- and low-quality pasture were $27.4 \%$ to $53.4 \%$ and $28.8 \%$ to $53.7 \%$, respectively. Turner et al. (2018) reported that the relaxation rate of switchgrass (Miscanthus) is not greatly affected by sample processing and is larger under higher water content. Moreover, the average relaxation rates of original and crushed Miscanthus at lower water content were $33.1 \%$ and $33.3 \%$, respectively, and the results of complete and crushed Panicum virgatum were $40.0 \%$ and $38.1 \%$, respectively.

The above studies imply that pressure maintenance and strain maintenance can both be used as stabilization processes to decrease the rebounding of post-compression straw blocks (Adapa et al. 2009; Wongsiriamnuay and Tippayawong 2015; Guo et al. 2016). However, the existing research has focused on variations of strain and stress after a single use of pressure or strain maintenance. There is little research about or even confusion between reality and literature about the mechanisms of improvement of the dimensional stability coefficient by the two processes or the combination of both processes. Thus, this study aims to clarify the relationships of stress and strain with time at the compression, stability, and rebounding stages compared among different compression processes, uncover the effects of pressure maintenance on the dimensional stability coefficient of post-compression chopped corn straw blocks, investigate the effects of strain maintenance on the dimensional stability coefficient of post-compression chopped corn straw blocks after the use of different compression processes, and compare the effects of different stabilization processes on the relaxation density of post-compression chopped corn straw blocks.

\section{EXPERIMENTAL}

\section{Materials}

The corn samples used in this study were planted in the experimental base of Jilin University (Changchun, China). In the test fields, the straw was chopped using the Yshaped gathering and crushing knives on a squared bundling machine (9YFSZ-2.2; Huade, Beijing, China). The chopped straw was stripped to a length of 10 to $100 \mathrm{~mm}$, a packing density of $40.8 \mathrm{~kg} / \mathrm{m}^{3}$, and moisture content of $16.5 \%$ w.b. The straw was not bundled or compacted but was picked manually, dried naturally for days at the doorway of the laboratory, and then collected as raw materials. The moisture contents of the raw materials were roughly detected and modulated in accordance with ASAE S358.2 (2008). The straw samples were placed in sealed bags and then stored at room temperature $\left(4^{\circ} \mathrm{C}\right)$ with a relative humidity of 52\% until use (Tumuluru et al. 2015).

\section{Test Machine}

The straw compression and test system (Fig. 1a to 1c) consisted of a ETM305D300 microcomputer control electric hydraulic universal tester (WANCE Inc., Shenzhen, China), a pressure head, a cabinet (360 $\mathrm{mm} \times 460 \mathrm{~mm}$ in cross-section, and $600 \mathrm{~mm}$ depth), film piezo resistance pressure sensors, error of $\leq \pm 3 \%$ (IMS-C20;I-Motion Inc., Suzhou, 
China), a laser displacement mini-sensor, repeatability of $300 \mu \mathrm{m}$ (HG-C1400; Panasonic, Osaka, Japan), a data acquisition card (USB-6351; National Instruments, Austin, TX, USA), and a displacement test sheet. The microcomputer control electric hydraulic universal tester provided the compression power and could control the compression procedures (Fig. 1d). In the middle of the cabinet, an 8-mm fissure was opened, which ensured the contactless migration of the displacement testing sheets, and then two film pressure sensors were stuck onto the displacement sheet (Fig. 1b). During compression and springback, the pressure stress was measured using the film pressure sensors, the compression and springback displacements were tested by the laser displacement minisensor, and the data of pressure stress and displacement were collected by the data acquisition card and displayed on Labview (National Instruments, 2018, Austin, TX, USA) in the form of curves (Fig. 1e). The tested data were all stored.

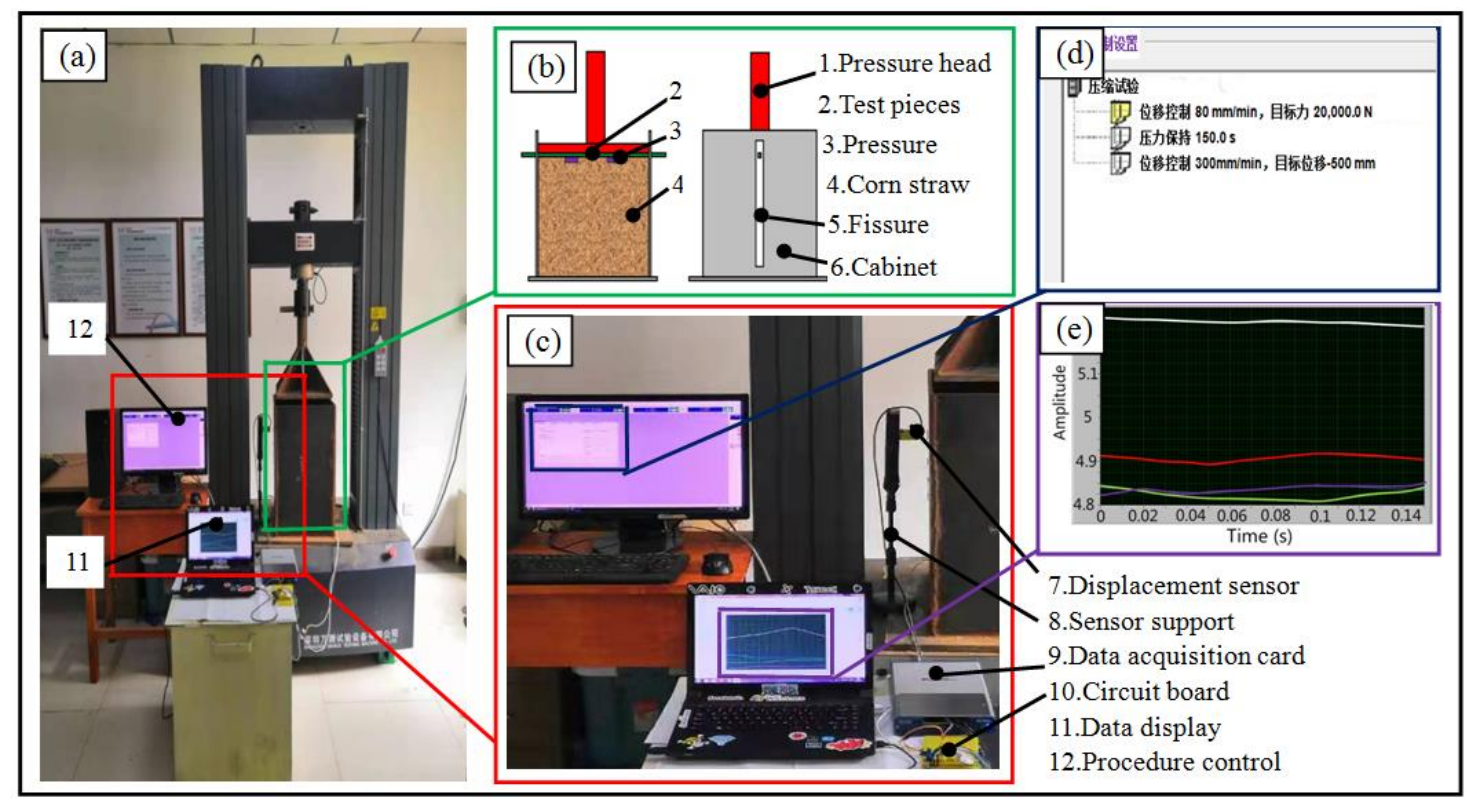

Fig. 1. (a) Straw compression and test system; (b) magnified I; (c) magnified II; (d) procedure control system; and (e) data display system

\section{Experimental Design}

The water contents of corn straw upon harvest were approximately $17 \% \mathrm{w} . \mathrm{b}$, but the best compression water content was $10 \%$ to $20 \%$ w.b. (Kaliyan and Morey 2009). Thus, the authors selected raw materials containing $18 \%$ w.b. water. The maximum compression stress and raw material feed quantity are important key influence factors relative to straw compression and directly affect the compression effect (Kaliyan and Morey 2009; Mostafa et al. 2019). Based on preliminary experiments, the maximum compression stresses of compression were set at 60.4, 12.8, and $181.2 \mathrm{kPa}$. Li (2011) selected the dose of 2 to $4 \mathrm{~kg}$ when studying crushed corn straw, so the authors set the dose of raw materials at $3 \mathrm{~kg}$. Time is a dependent variable of pressure maintenance and strain maintenance. In the existing research, the largest pressure maintenance time is 20s (Chen et al. 2016) or $90 \mathrm{~s}$ (Liu et al. 2017), and the commonly-used strain maintenance time is $60 \mathrm{~s}$ (Nona et al. 2014), $150 \mathrm{~s}$ (Herak et al.2015), $200 \mathrm{~s}$ (Hu et al. 2009), $240 \mathrm{~s}$ (Shaw 2008), or $300 \mathrm{~s}$ (Turner et al. 2018). Based on the requirement of practical energy consumption and compression efficiency, in this study the authors set the maximum 
pressure maintenance or strain maintenance at $150 \mathrm{~s}$. When the effects of different stabilization processes on the relaxation density of post-compression straw blocks were compared, the same pressure maintenance time and strain maintenance time during CCPS were selected, which took into account the same compression efficiency and both accounted for half of the stabilization time. After the preliminary experiments, the authors chose the rebounding time of post-compression straw blocks to be $300 \mathrm{~s}$. Each test was repeated six times and the average was determined. When compressed, the temperature of corn straw is $15^{\circ} \mathrm{C}$.

\section{Methods}

\section{Test procedures}

Figure 2 shows the straw compression and test procedures. After the raw materials were fed, the universal testing machine and the test facility were started, and the pressure head compressed the raw materials at a constant speed of $80 \mathrm{~mm} / \mathrm{min}(\mathrm{Hu} 2008)$. When the compression stress reached the preset maximum, one of four process routes was initiated: no treatment, pressure maintenance, strain maintenance, pressure maintenance followed by strain maintenance, and then (in all routes) the pressure head returned to the initial position at the constant speed of $300 \mathrm{~mm} / \mathrm{min}$.

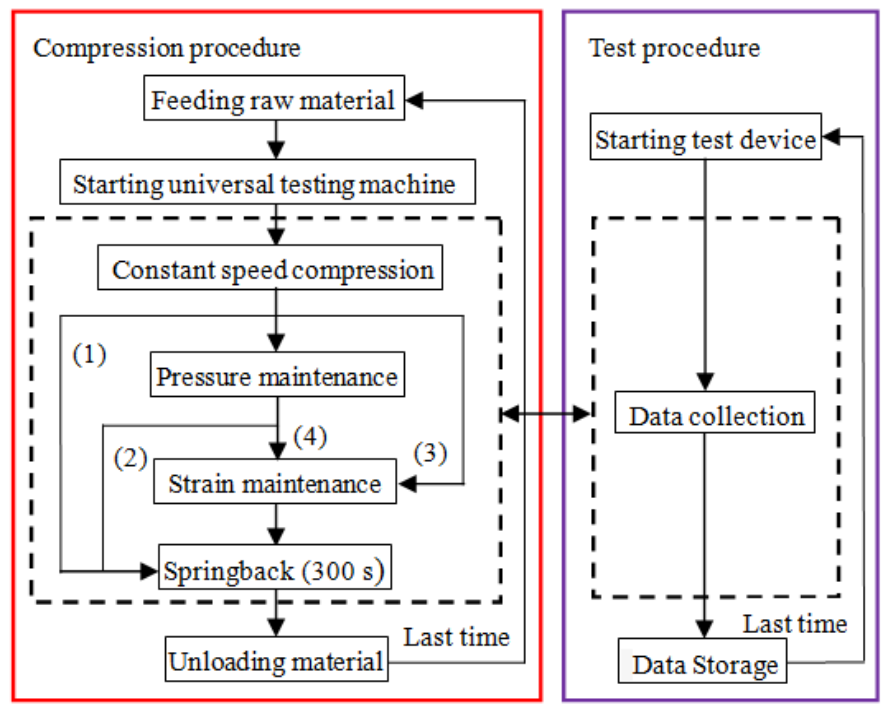

Fig. 2. Compression and test procedure

To avoid the effect of mould wall friction on rebounding of post-compression straw blocks, the authors withdrew the mould side walls before rebounding. The compression of straw inside the moulds was a one-dimensional size change process, and the rebounding directions of the compressed straw were the compression direction and lateral direction. It was detected from pretests that the lateral rebounding of compressed straw blocks was very small, and the lateral rebounding did not significantly change with the stabilization mode or stabilization time. Throughout the tests, stresses and displacements at the compression stress relaxation and rebounding stages were detected. The stress and strain of straw compression were calculated according to Eqs. 1 and 2 (Herak et al. 2015; Song et al. 2015),

$$
\sigma(t)=\frac{F_{\mathrm{t}}}{S}
$$




$$
\varepsilon(t)=\frac{L_{\mathrm{pt}}-L_{0}}{H_{0}}
$$

where $\sigma$ is the compression stress of corn stover at time $t(\mathrm{~s})(\mathrm{kPa}), F_{\mathrm{t}}$ is the compression force at time $t(\mathrm{~s})(\mathrm{N}), S$ is the cross-sectional area of compression box (i.e., 165,600 $\mathrm{mm}^{2}$ ) $\left(\mathrm{mm}^{2}\right), \varepsilon$ is the strain (-), $H_{0}$ is the initial height of corn stover $(\mathrm{mm}), L_{\mathrm{pt}}$ is the displacement between straw surface and testing point at compression time $t(\mathrm{~s})(\mathrm{mm})$, and $L_{0}$ is the initial displacement between straw surface and testing point $(\mathrm{mm})$.

\section{Constitutive Models}

Constitutive models aim to use mathematical equations and mechanical elements to build models that can explain straw compression (Mohsenin and Zaske 1976; Wang 2007; Li et al. 2012). The commonly used mechanical elements include spring, damping, and sliders (Yang 2010).

\section{Pressure maintenance model}

In the existing research, constitutive models on creep of viscoelastic materials have been much studied, and the Kelvin model is a necessary one (Fig. 3a). This model consists of one spring and one damping in parallel connection, and its constitutive equation is shown in Eq. 3 (Yang 2010). One spring series-connection Kelvin model constitutes a Naramura model, and it can uncover the elastic-retarding and elastic creep process. Its constitutive equation (Fig. 3b) is expressed in Eq. 4. One spring series-connection Kelvin model and one damping constitute a Burgers model or four-element model, which can be used to describe the elastic deformation-viscous flow. Its deformation consists of three parts, including instantaneous deformation, viscoelastic deformation with the increasing deformation rate, and viscous deformation. Its constitutive equation (Fig. 3c) is listed in Eq. 5 (Xu et al. 2010; Yin et al. 2016). During the pressure maintenance of compressed straw, there was friction between straw and mould inner walls, but since the straw was already compressed, the dominant counterforce during pressure maintenance was the acting force between straw and straw. Thus, to simplify the models and computation, the friction was ignored during the establishment of pressure maintenance models. Such simplification can also be found in some existing studies (Li 2011; Yang 2010; Xu et al. 2010; Yin et al.2016).

$$
\begin{aligned}
& \varepsilon_{\mathrm{A}}\left(t_{\mathrm{C}}\right)=\frac{\sigma_{\mathrm{MC}}}{E_{\mathrm{CA}}} \cdot\left(1-e^{-\frac{E_{\mathrm{CA}}}{\eta_{\mathrm{CA}}} \cdot t_{\mathrm{C}}}\right) \\
& \varepsilon_{\mathrm{B}}\left(t_{\mathrm{C}}\right)=\frac{\sigma_{\mathrm{MC}}}{E_{\mathrm{CB} 1}} \cdot\left(1-e^{-\frac{E_{\mathrm{CB} 1}}{\eta_{\mathrm{CB}}} \cdot t_{\mathrm{C}}}\right)+\frac{\sigma_{\mathrm{MC}}}{E_{\mathrm{CB} 2}} \\
& \varepsilon_{\mathrm{C}}\left(t_{\mathrm{C}}\right)=\frac{\sigma_{\mathrm{MC}}}{E_{\mathrm{CC} 1}} \cdot\left(1-e^{-\frac{E_{\mathrm{CC} 1}}{\eta_{\mathrm{CC} 1}} \cdot t_{\mathrm{C}}}\right)+\frac{\sigma_{\mathrm{MC}}}{\eta_{\mathrm{CC} 2}} \cdot t_{\mathrm{C}}+\frac{\sigma_{\mathrm{MC}}}{E_{\mathrm{CC} 2}}
\end{aligned}
$$

In the above equations, $\varepsilon_{\mathrm{A}}, \varepsilon_{\mathrm{B}}$, and $\varepsilon_{\mathrm{C}}$ are strain during keeping pressure phase(-); $\sigma_{\mathrm{MC}}$ is max compression stress $(\mathrm{kPa}) ; E_{\mathrm{CA}}, E_{\mathrm{CB} 1}, E_{\mathrm{CB} 2}, E_{\mathrm{CC} 1}$, and $E_{\mathrm{CC} 2}$ are moduli of elasticity for the creep models branches $(\mathrm{kPa}) ; \eta_{\mathrm{CA}}, \eta_{C B}, \eta_{\mathrm{CC} 1}$, and $\eta_{\mathrm{CC} 2}$ are coefficients of normal viscosity of the creep models branches $(\mathrm{kPa} \bullet \mathrm{s})$; and $t_{\mathrm{C}}$ is pressure maintenance time $(\mathrm{s})$. 


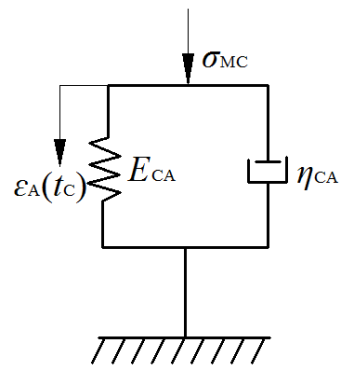

(a)

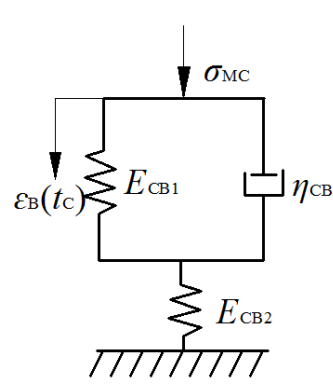

(b)

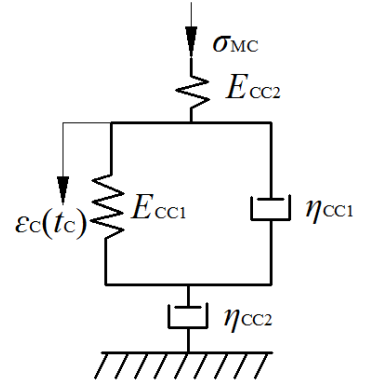

(c)

Fig. 3. Pressure maintenance model

\section{Strain maintenance model}

Strain maintenance is essentially stress relaxation. The Maxwell model consists of a spring and a damping in series connection and is a necessary part of the stress relaxation model (Yang et al. 1996; Wang et al. 1997). The post-compression straw stress relaxation model may consist of one or multiple Maxwell models, and the spring and can be used to describe the stress relaxation of viscoelastic materials (Yang 2010). The commonly-used stress relaxation models include the Wiechert model A, Wiechert model B, and secondorder Maxwell model. The Wiechert model A is a Maxwell model connected in parallel with a spring (Fig. 4a), and its constitutive equation is shown in Eq. 6 (Chen et al. 2013; Herak et al. 2015). Wiechert model B consists of two Maxwell models connected in parallel with a spring (Fig. 4b), and its constitutive equation is shown in Eq. 7 (Chen et al. 2013; Herak et al .2015; Fang et al. 2018). The second-order Maxwell model consists of two Maxwell models connected in parallel (Fig. 4c), and its constitutive equation is shown in Eq. 8 (Ma et al. 2016),

$$
\begin{aligned}
& \sigma_{\mathrm{A}}\left(t_{\mathrm{R}}\right)=E_{\mathrm{A} 1} \cdot \varepsilon_{\mathrm{M}} \cdot e^{-\frac{E_{\mathrm{A} 1}}{\eta_{\mathrm{A} 1}} t_{\mathrm{R}}}+E_{\mathrm{A} 2} \cdot \varepsilon_{\mathrm{M}} \\
& \sigma_{\mathrm{B}}\left(t_{\mathrm{R}}\right)=E_{\mathrm{B} 1} \cdot \varepsilon_{\mathrm{M}} \cdot e^{-\frac{E_{\mathrm{B} 1}}{\eta_{\mathrm{B} 1}} \cdot t_{\mathrm{R}}}+E_{\mathrm{B} 2} \cdot \varepsilon_{\mathrm{M}} \cdot e^{-\frac{E_{\mathrm{B} 2}}{\eta_{\mathrm{B} 2}} \cdot t_{\mathrm{R}}}+E_{\mathrm{B} 3} \cdot \varepsilon_{\mathrm{M}} \\
& \sigma_{\mathrm{C}}\left(t_{\mathrm{R}}\right)=E_{\mathrm{C} 1} \cdot \varepsilon_{\mathrm{M}} \cdot e^{-\frac{E_{\mathrm{C} 1}}{\eta_{\mathrm{C} 1}} \cdot t_{\mathrm{R}}}+E_{\mathrm{C} 2} \cdot \varepsilon_{\mathrm{M}} \cdot e^{-\frac{E_{\mathrm{C} 2}}{\eta_{\mathrm{C} 2}} \cdot t_{\mathrm{R}}}
\end{aligned}
$$

where $\sigma_{\mathrm{A}}, \sigma_{\mathrm{B}}$, and $\sigma_{\mathrm{C}}$ are relaxation stress of corn stover at strain maintenance time $t$ (s) $(\mathrm{kPa}) ; E_{\mathrm{A} 1}, E_{\mathrm{A} 2}, E_{\mathrm{B} 1}, E_{\mathrm{B} 2}, E_{\mathrm{B} 3}, E_{\mathrm{C} 1}$, and $E_{\mathrm{C} 2}$ are moduli of elasticity for the relaxation models branches $(\mathrm{kPa}) ; \eta_{\mathrm{A} 1}, \eta_{\mathrm{B} 1}, \eta_{\mathrm{B} 2}, \eta_{\mathrm{C} 1}$, and $\eta_{\mathrm{C} 2}$ are coefficients of normal viscosity of the relaxation models branches $(\mathrm{kPa} \bullet \mathrm{s}) ; \varepsilon_{\mathrm{M}}$ is max strain of compression (-), and $t_{\mathrm{R}}$ is strain maintenance time (s).

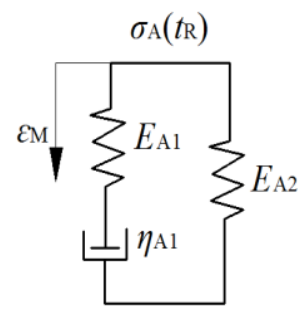

(a)

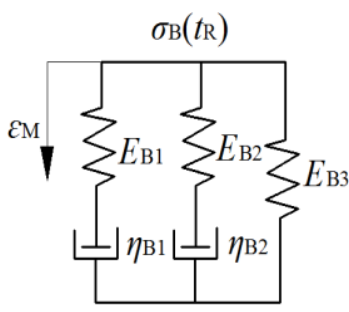

(b)

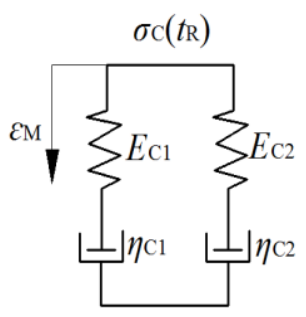

(c)

Fig. 4. Strain maintenance model 


\section{Evaluation Indices}

\section{Stress relaxation evaluation indices}

The stress relaxation rate is the degree of stress relaxation within unit time, or namely the percentage of relaxed stress after a period of time accounting for the initial stress. Stress relaxation rate was calculated using Eq. 9 (Johnson et al. 2013; Guo et al. 2016; Turner et al. 2018),

$$
\alpha=\frac{\sigma_{0}-\sigma_{\mathrm{t}}}{\sigma_{0}} \times 100
$$

where $\alpha$ is stress relaxation rate $(\%), \sigma_{0}$ is initial stress $(\mathrm{kPa})$, and $\sigma_{\mathrm{t}}$ is the stress after strain maintenance time $t(\mathrm{~s})(\mathrm{kPa})$.

\section{Dimensional stability coefficient}

The dimensional stability coefficient measures the ratio of rebounding displacement after compression to the compression displacement at the constant speed stage and can reflect compression and springback displacement, the dimensional stability coefficient of post-compression straw blocks and useful work during compression,

$$
\beta=\left[1-\frac{\left(L_{\mathrm{S}}-L_{0}\right)}{\left(L_{\mathrm{C}-L_{0}}\right)}\right] \times 100 \%
$$

where $\beta$ is the dimensional stability coefficient of post-compression straw blocks $(\%), L_{\mathrm{S}}$ is the displacement from the straw surface to the test point after $300 \mathrm{~s}$ of rebounding $(\mathrm{mm})$, and $L_{C}$ is the displacement between the straw surface after the constant-speed compression stage and testing point (mm).

\section{Relaxation density}

Relaxation density is the density of rebounding after the pressure head leaves the compressed straw. In this study, relaxation density was measured at $300 \mathrm{~s}$ after the rebounding. Relaxation density is one of the major indices that implies the compression effect of straw. Since the lateral rebounding of post-compression straw blocks was not much influential and did not significantly change with the stabilization mode or stabilization time, lateral rebounding was ignored during computation of relaxation density. It can be computed as follows in Eq. 11 (Wongsiriamnuay and Tippayawong 2015; Guo et al. 2016),

$$
\rho_{S}=\frac{m \times 10^{9}}{\left(H-L_{S}\right) \cdot S}
$$

where $\rho_{S}$ is the relaxation density of post-compression corn straw blocks $\left(\mathrm{kg} / \mathrm{m}^{3}\right), H$ is the displacement between the corn straw bottom and testing point ( $\mathrm{mm})$, and $m$ is the feeding mass of chopped corn straw $(\mathrm{kg})$.

\section{Data Analysis}

The least square method is commonly used to assign values to parameters of curve fitting and rheological models. Thus, the least squares method of Levenberg-Marquardt in the nonlinear fitting module on Origin 8.0 (Data Analysis and Graphing, OriginLab, Northampton, MA, USA) was selected, which could efficiently solve the initial value selection (Ma and Daemen 2006; Theerarattananoon et al. 2011; Yu et al. 2019). Data were analyzed by using the analysis of variance (ANOVA) and least-significant difference (LSD) at the 0.05 level procedures in Origin 8.0 (Theerarattananoon et al. 2011). 
Correlation analysis using the Grey correlation method was calculated to use Grey correlation formula of Deng steps (Deng 1986; Zhang et al. 2018).

\section{RESULTS AND DISCUSSION}

\section{Compression Process Analysis}

Under different compression and stabilization processes (CC, CCS, CCP, and CCPS), the temporal changes of stress and strain of chopped corn straw at different stages are illustrated in Fig. 5(a) and Fig. 5(b), respectively. At the constant-speed compression stage, the strain linearly increased, while the pressure stress increased slowly within the first $150 \mathrm{~s}$ of compression and quickly at the late stage. At the early stage of compression, the straw was relaxed to remove the inter- and intra-straw gaps and to create mutual contact between straw. At the later stage, the main aim was the mutual clinging or inlay of straw grains (Kaliyan and Morey 2009; Hou 2013). At the pressure maintenance stage, the maximum compression stress was unchanged, and strain increased with prolonged time. Strain increased at a large rate at an early stage, but then it stabilized with time. At the strain maintenance stage, strain was unchanged, while stress gradually weakened. Relaxation was severe at the early stage, but then it decelerated with time. Guo et al. (2016) found that the stress relaxation rate after $60 \mathrm{~s}$ of relaxation was approximately $45 \%$. Gong (2017) found that within the first 20 s of stress relaxation, the residual stress in the materials was transiently attenuated, and approximately $80 \%$ of residual stress disappeared. At the rebounding stage, stress dropped to 0 within a short time, and strain first decreased rapidly and then stabilized after $240 \mathrm{~s}$ of rebounding.

The strain after rebounding maximized under CCPS, followed by CCS, CCP, and CC (Fig. 5(b)), which indicated that pressure maintenance and strain maintenance processes could both remarkably decrease the rebounding of post-compression chopped corn straw and increase relaxation density. This result was consistent with existing literature (Mani et al. 2006; Adapa et al. 2009; Wongsiriamnuay and Tippayawong 2015).
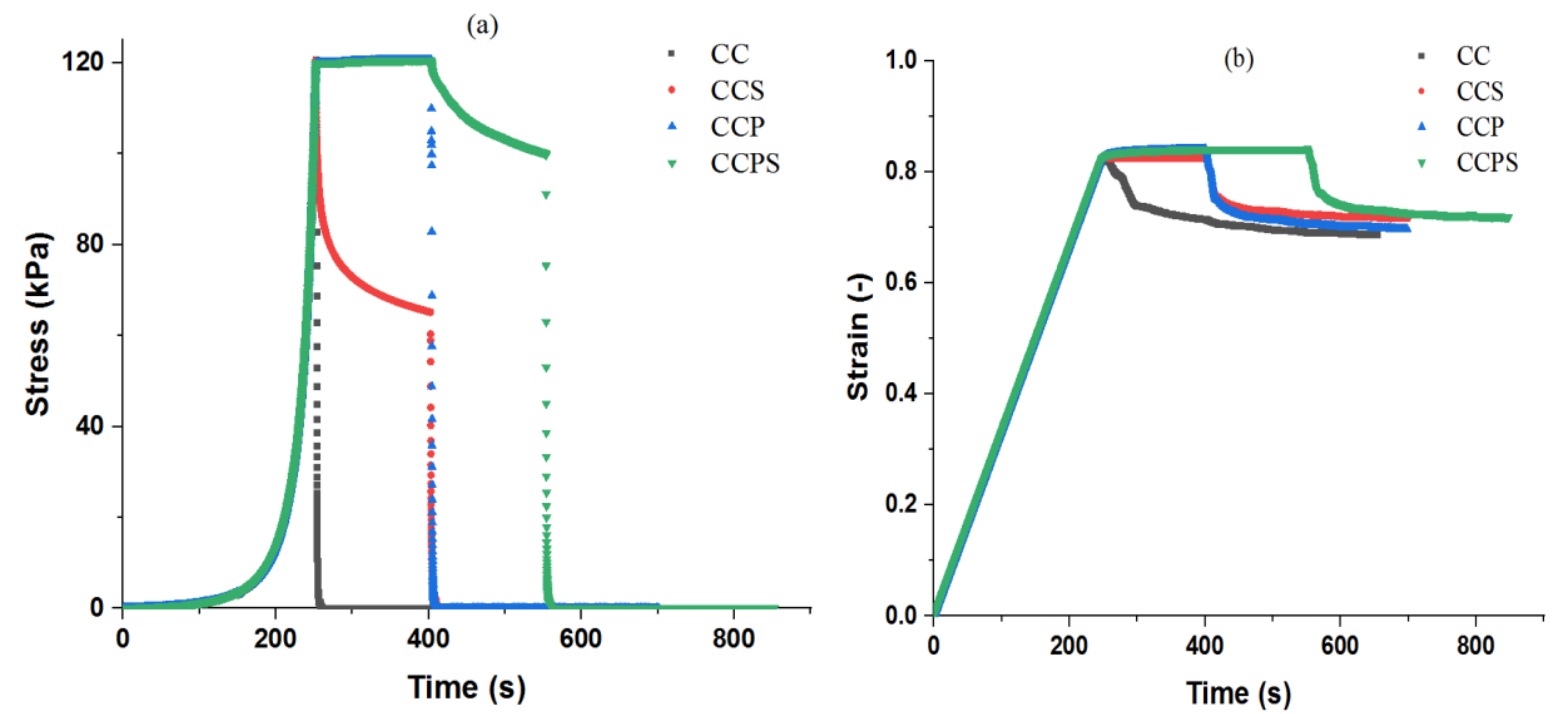

Fig. 5. (a) Relationship between stress and time; (b) relationship between strain and time 


\section{Mechanism of Dimensional Stability by Pressure Maintenance}

Under the maximum compression stresses of $60.4,120.8$, and $181.2 \mathrm{kPa}$, relationships between strain and pressure maintenance time at different stages, as well as the model fitting, are illustrated in Fig. 6. As the pressure maintenance time was prolonged, the strain increased, but the rate of increase decreased. The compression strain at the first $25 \mathrm{~s}$ of pressure maintenance accounted for $75 \%$ of total strain at this stage, and after 150 $\mathrm{s}$, the strain increased $2.78,1.87$, and 1.67 , the maximum crushing stress increased, and the magnitude of pressure maintenance strain decreased. The reason for this was that at large maximum compression stresses, the straw was already well compacted at the constantspeed compression stage, so the increasing rate of strain at the pressure maintenance stage decreased. Liu et al. (2017) studied the pressure maintenance of fibrillated corn straw and found that the pressure at 6.22 to $9.33 \mathrm{MPa}$ did not greatly affect the post-compression straw masses.

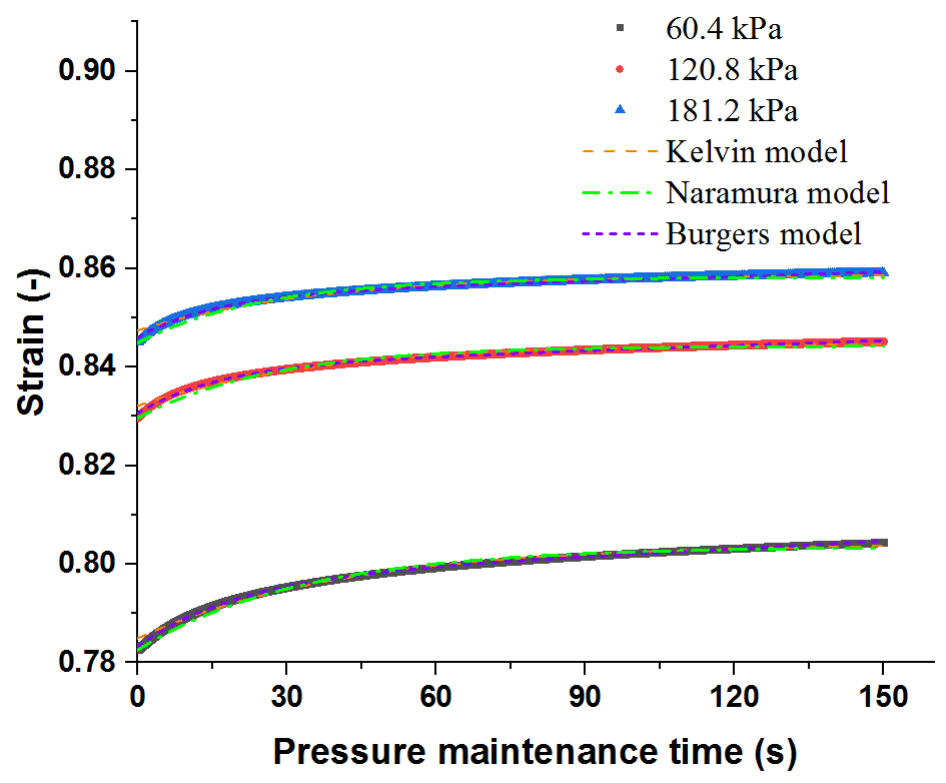

Fig. 6. Relationship between stress and pressure maintenance time for max compression stresses: $60.4,120.8$, and $181.2 \mathrm{kPa}$

Table 1 lists the model parameters determined from the method of undetermined coefficients as well as the coefficient of determination. Clearly, the Burgers model could describe constant-speed compression straw at the pressure maintenance stage $\left(\mathrm{R}^{2}>0.990\right)$, followed by the Naramura model and the Kelvin model. Li (2011) also found that the Burgers model could elaborate the crushed corn straw at the pressure maintenance stage. Model fitting showed that the strain of pressure maintenance straw consisted of instantaneous elastic strain, viscoelastic strain, and viscous strain (Xu et al. 2010; Yin et al. 2016). As the compression stress increased, the instantaneous elastic modulus, viscoelastic elastic modulus, viscoelastic viscosity, and viscous viscosity of the constitutive model were all enhanced. The reason for this was that as the maximum compression stress increased, the strain of post-compression straw blocks also increased, and the elasticity, viscoelasticity, and viscosity were all strengthened accordingly. 
Table 1. Parameter and Coefficient of Determination of Kelvin Model, Naramura Model, and Burgers Model During Keeping Compression Stress Phase Under Different Max Compression Stresses (60.4 kPa,120.8 kPa, and $181.2 \mathrm{kPa}$ )

\begin{tabular}{|c|c|c|c|c|c|c|c|c|c|c|c|c|}
\hline \multirow{2}{*}{\begin{tabular}{|c|}
\multicolumn{1}{|c|}{ Max } \\
Compression \\
Stress $(\mathrm{kPa})$
\end{tabular}} & \multicolumn{3}{|c|}{ Kelvin Model } & \multicolumn{4}{|c|}{ Naramura Model } & \multicolumn{5}{|c|}{ Burgers Model } \\
\hline & \begin{tabular}{|c|}
$E_{\mathrm{CA}}$ \\
$(\mathrm{kPa})$
\end{tabular} & $\begin{array}{c}\eta_{\mathrm{CA}} \\
(\mathrm{kPa} \cdot \mathrm{s})\end{array}$ & $\mathrm{R}^{2}$ & $\begin{array}{l}E_{\mathrm{CB} 1} \\
(\mathrm{kPa})\end{array}$ & $\begin{array}{c}E_{\mathrm{CB} 2} \\
(\mathrm{kPa})\end{array}$ & $\begin{array}{c}\eta_{\mathrm{CB}} \\
(\mathrm{kPa} \cdot \mathrm{s})\end{array}$ & $\mathrm{R}^{2}$ & $\begin{array}{l}E_{\mathrm{CC} 1} \\
(\mathrm{kPa})\end{array}$ & \begin{tabular}{|l|}
$E_{\mathrm{CC} 2}$ \\
$(\mathrm{kPa})$ \\
\end{tabular} & $\begin{array}{c}\eta_{\mathrm{cc} 1} \\
(\mathrm{kPa} \cdot \mathrm{s})\end{array}$ & $\begin{array}{c}\eta_{\mathrm{CCD} 2} \\
(\mathrm{kPa} \cdot \mathrm{s})\end{array}$ & $\mathrm{R}^{2}$ \\
\hline 60.4 & $\begin{array}{c}2.89 \mathrm{E} \\
+3\end{array}$ & $9.60 \mathrm{E}$ & 0.981 & $\begin{array}{l}3.14 \\
E+3\end{array}$ & $\begin{array}{l}2.58 \\
E+5\end{array}$ & $\begin{array}{l}1.29 \\
E+5\end{array}$ & 0.991 & $\begin{array}{l}4.37 \\
E+3\end{array}$ & $\begin{array}{l}8.02 \\
E+4\end{array}$ & $\begin{array}{l}3.48 \\
E+5\end{array}$ & $\begin{array}{l}1.21 \\
E+6\end{array}$ & 0.999 \\
\hline 120.8 & $\begin{array}{c}8.26 \mathrm{E} \\
+3\end{array}$ & 22 & 0.960 & \begin{tabular}{|l}
9.54 \\
$E+3$
\end{tabular} & $\begin{array}{l}4.89 \\
E+4\end{array}$ & $\begin{array}{l}3.48 \\
E+5\end{array}$ & 0.984 & $\begin{array}{l}1.26 \\
E+4\end{array}$ & $\begin{array}{l}1.20 \\
E+5\end{array}$ & $\begin{array}{l}1.06 \\
E+6\end{array}$ & $\begin{array}{l}3.53 \\
E+6\end{array}$ & 0.997 \\
\hline 181.2 & $\begin{array}{c}1.37 \mathrm{E} \\
+4\end{array}$ & & 0.954 & \begin{tabular}{|l|}
1.60 \\
$E+4$ \\
\end{tabular} & $\begin{array}{l}7.41 \\
E+4 \\
\end{array}$ & $\begin{array}{l}5.79 \\
E+5\end{array}$ & 0.982 & $\begin{array}{l}2.10 \\
E+4 \\
\end{array}$ & \begin{tabular}{|l|}
1.74 \\
$E+5$
\end{tabular} & $\begin{array}{l}1.80 \\
E+6\end{array}$ & $\begin{array}{l}5.85 \\
E+6\end{array}$ & 0.9 \\
\hline
\end{tabular}

The effects of pressure maintenance time on the dimensional stability coefficient of post-compression straw blocks are illustrated in Fig. 7. As the maximum compression stress increased, the dimensional stability coefficient decreased. The reason for this was that the dimensional stability coefficient was decided jointly by the constant-speed compression displacement and rebounding displacement, and as the maximum compression stress increased, the compression displacement and rebounding quantity both were maximized, and the increase of relative rebounding displacement was also large. As the pressure maintenance time was prolonged, the dimensional stability coefficient of postcompression straw blocks was enhanced, and after $150 \mathrm{~s}$ of pressure maintenance, it increased $1.48 \%, 1.87 \%$, and $2.83 \%$. Chen et al. (2016) found that the dimensional stability coefficient of post-compression biomass at several days after mould unloading first increased and then decreased with the prolonging of pressure maintenance time.

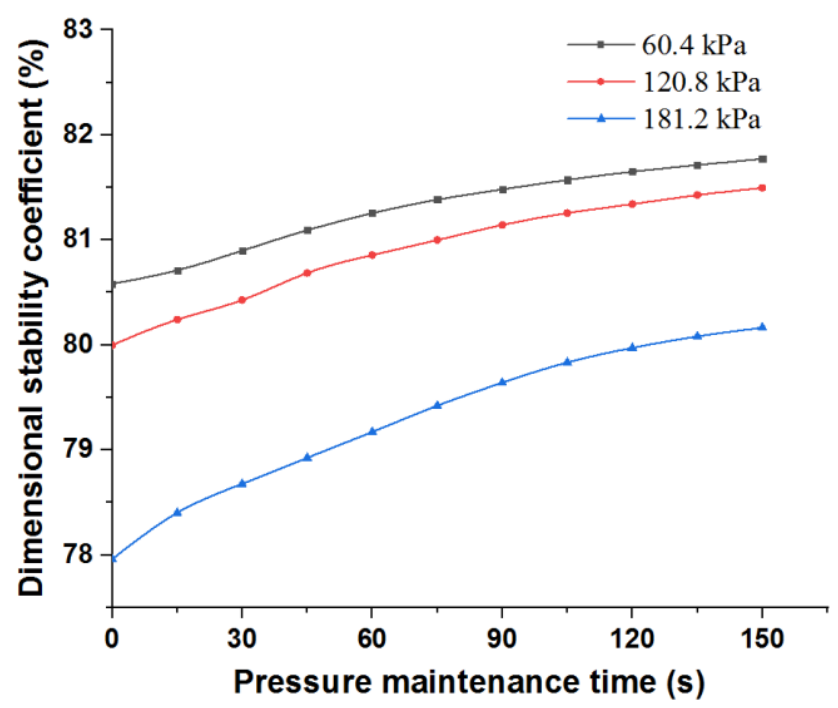

Fig. 7. Relationship between stability coefficient and pressure maintenance time

The above analysis suggested that pressure maintenance could further compress the straw compressed at constant velocity, strengthen the compression strain, and decrease the rebounding displacement of post-compression straw blocks. The compression effect was strengthened from two aspects, including the increased compression displacement and the shortened rebound displacement. 


\section{Mechanism of Dimensional Stability by Strain Maintenance}

During the compression process of chopped corn straw, strain maintenance could be conducted after constant speed compression or after pressure maintenance. According to the above analyses, the strain maintenance under different compression processes affected the dimensional stability of post-compression straw blocks differently. Figure 8 shows the relationships between compression stress and strain maintenance time at the strain maintenance stage under CCS or CCPS. The existing stress relaxation models (Wiechert model A, Wiechert model B, and second-order Maxwell model) were used infitting. The model parameters and coefficient of determination after fitting are listed in Table 2 . Wiechert model B fit the best $\left(\mathrm{R}^{2}>0.990\right)$, followed by Wiechert model A and second-order Maxwell model. Thus, Wiechert model B was adopted to describe the strain maintenance process of post-compression chopped corn straw blocks. Herak et al. (2015) found that Wiechert model B $\left(\mathrm{R}^{2}>0.99\right)$ outperformed Wiechert model A in characterizing the relaxation of massive seeds of Jatropha curcas. Ma et al. (2016) reported that the second-order Maxwell model was applicable in describing the stress relaxation process of corn straw with or without vibration $\left(\mathrm{R}^{2}>0.9\right)$, but the model marks differed. Under the same compression mode, as maximum compression stress increased, the spring elastic coefficient and damping viscosity coefficient in Wiechert model B both increased, which was because the increase in maximum compression stress led to an increase in viscoelasticity of post-compression straw blocks.

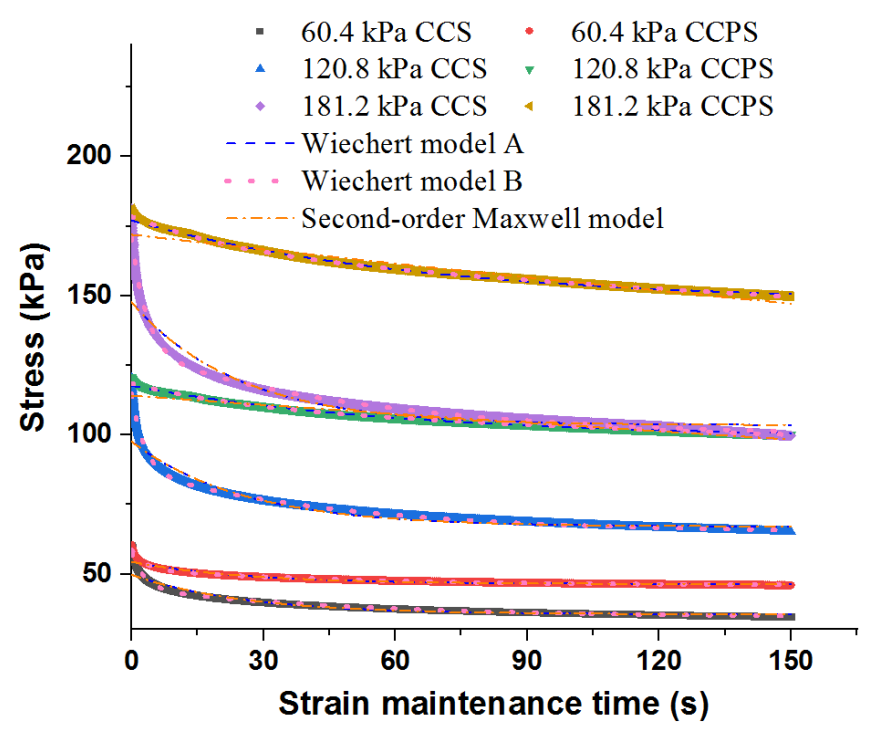

Fig. 8. Relationship between stress and strain maintenance time under two different compression methods (CCS and CCPS) for max compression stresses: $60.4,120.8$, and $181.2 \mathrm{kPa}$

At the maximum compression stresses of $60.4,120.8$, and $181.2 \mathrm{kPa}$, the relaxation rates after varying strain maintenance times at the strain maintenance stage under CCS or CCPS are listed in Table 3. The relaxation rate decreased with time, which was consistent with studies by Chen et al. (2013) and Guo et al. (2016). As maximum compression stress increased, stress relaxation rate under CCS increased, but that under CCPS decreased. This was because after constant-speed compression during CCS, the larger compression stress led to higher elastic force of postcompression straw blocks, but the proportion in the maximum compression stress 
decreased. However, after pressure maintenance, compression displacement further increased and elasticity of post-compression straw blocks was enhanced.

Table 2. Parameter of Wiechert Model A, Wiechert Model B, Second-order Maxwell Model Under Different Max Compression Stresses $(60.4,120.8$, and $181.2 \mathrm{kPa}$ ) and Compression Methods

\begin{tabular}{|c|c|c|c|c|c|c|c|}
\hline \multirow{2}{*}{ Model } & \multirow{2}{*}{ Parameter } & \multicolumn{2}{|c|}{$60.4 \mathrm{kPa}$} & \multicolumn{2}{c|}{$120.8 \mathrm{kPa}$} & \multicolumn{2}{c|}{$181.2 \mathrm{kPa}$} \\
\cline { 2 - 8 } & & $\mathrm{CCS}$ & $\mathrm{CCPS}$ & $\mathrm{CCS}$ & $\mathrm{CCPS}$ & $\mathrm{CCS}$ & $\mathrm{CCPS}$ \\
\hline \multirow{4}{*}{$\begin{array}{l}\text { Wiechert } \\
\text { Model A }\end{array}$} & $E_{\mathrm{A} 1}(\mathrm{kPa})$ & 19.70 & 10.77 & 37.57 & 22.58 & 52.50 & 34.42 \\
\cline { 2 - 8 } & $E_{\mathrm{A} 2}(\mathrm{kPa})$ & 49.42 & 62.72 & 82.32 & 118.80 & 122.58 & 171.86 \\
\cline { 2 - 8 } & $\eta_{\mathrm{A}}(\mathrm{kPa} \cdot \mathrm{s})$ & 507.40 & 278.25 & $\begin{array}{c}948.7 \\
9\end{array}$ & 1429.67 & $\begin{array}{c}1271.0 \\
0\end{array}$ & 2289.66 \\
\cline { 2 - 8 } & $\mathrm{R}^{2}$ & 0.94 & 0.942 & 0.94 & 0.996 & 0.932 & 0.996 \\
\hline \multirow{4}{*}{$\begin{array}{c}\text { Wiechert } \\
\text { Model B }\end{array}$} & $E_{\mathrm{B} 1}(\mathrm{kPa})$ & 17.71 & 9.48 & 33.76 & 11.20 & 48.6 & 17.04 \\
\cline { 2 - 8 } & $E_{\mathrm{B} 2}(\mathrm{kPa})$ & 14.51 & 8.00 & 27.58 & 39.59 & 36.4 & 117.06 \\
\cline { 2 - 8 } & $E_{\mathrm{B} 3}(\mathrm{kPa})$ & 47.95 & 61.98 & 79.59 & 91.68 & 117.57 & 73.83 \\
\cline { 2 - 8 } & $\eta_{\mathrm{B} 1}(\mathrm{kPa} \cdot \mathrm{s})$ & 51 & 27.57 & 97.01 & 304.85 & 163 & 471.18 \\
\cline { 2 - 8 } & $\eta_{\mathrm{B} 2}(\mathrm{kPa} \cdot \mathrm{s})$ & 713 & 383.43 & 1314 & $1.82 \mathrm{E}+4$ & 1975 & $1.1 \mathrm{E}+5$ \\
\cline { 2 - 8 } & $\mathrm{R}$ & 0.996 & 0.997 & 0.996 & 0.993 & 0.994 & 0.999 \\
\hline \multirow{4}{*}{$\begin{array}{c}\text { Second-order } \\
\text { Maxwell } \\
\text { Model }\end{array}$} & $E_{\mathrm{C} 1}(\mathrm{kPa})$ & 14.17 & 10.77 & 37.56 & 68.62 & 122.57 & 100.16 \\
\cline { 2 - 8 } & $E_{\mathrm{C} 2}(\mathrm{kPa})$ & 49.45 & 62.76 & 82.31 & 68.62 & 52.24 & 100.16 \\
\cline { 2 - 8 } & $\eta_{\mathrm{C} 1}(\mathrm{kPa} \cdot \mathrm{s})$ & 507.89 & 278.55 & 949.8 & $6.90 \mathrm{E}+4$ & 1265.8 & $9.66 \mathrm{E}+4$ \\
\cline { 2 - 7 } & $\eta_{\mathrm{C} 2}(\mathrm{kPa} \cdot \mathrm{s})$ & $4 \mathrm{E}+28$ & $1.40 \mathrm{E}+23$ & $9 \mathrm{E}+27$ & 68956.6 & $1 \mathrm{E}+21$ & 96594.8 \\
\cline { 2 - 8 } & $\mathrm{R}^{2}$ & 0.94 & 0.942 & 0.94 & 0.93 & 0.932 & 0.935 \\
\hline
\end{tabular}

Table 3. Stress Relaxation Rate of CCS and CCPS Compression Under Different Compression Stresses $(60.4,120.8$, and $181.2 \mathrm{kPa})$

\begin{tabular}{|c|c|c|c|c|c|c|}
\hline $\begin{array}{c}\text { Max } \\
\text { Compression } \\
\text { Stress }(\mathrm{kPa})\end{array}$ & $\begin{array}{c}\text { Compression } \\
\text { Methods }\end{array}$ & $30 \mathrm{~s}$ & $60 \mathrm{~s}$ & $90 \mathrm{~s}$ & $120 \mathrm{~s}$ & $150 \mathrm{~s}$ \\
\hline \multirow{2}{*}{60.4} & CCS & $34 \pm 0.51^{\mathrm{b}}$ & $37.8 \pm 0.63^{\mathrm{b}}$ & $40 \pm 0.36^{\mathrm{b}}$ & $41.4 \pm 0.47^{\mathrm{b}}$ & $42.6 \pm 0.28^{\mathrm{b}}$ \\
\cline { 2 - 7 } & CCPS & $9 \pm 0.22^{\mathrm{a}}$ & $13.2 \pm 0.31^{\mathrm{a}}$ & $15.5 \pm 0.19^{\mathrm{a}}$ & $17.4 \pm 0.32^{\mathrm{a}}$ & $18.7 \pm 0.42^{\mathrm{a}}$ \\
\hline \multirow{2}{*}{120.8} & $\mathrm{CCS}$ & $35.75 \pm 0.66^{\mathrm{b}}$ & $39 \pm 0.28^{\mathrm{b}}$ & $41.4 \pm 0.49^{\mathrm{b}}$ & $43 \pm 0.58^{\mathrm{b}}$ & $44 \pm 0.53^{\mathrm{b}}$ \\
\cline { 2 - 7 } & $\mathrm{CCPS}$ & $8.65 \pm 0.42^{\mathrm{a}}$ & $11.75 \pm 0.38^{\mathrm{a}}$ & $14.7 \pm 0.42^{\mathrm{a}}$ & $16 \pm 0.39^{\mathrm{a}}$ & $17.75 \pm 0.50^{\mathrm{a}}$ \\
\hline \multirow{2}{*}{181.2} & $\mathrm{CCS}$ & $36 \pm 0.54^{\mathrm{b}}$ & $39.6 \pm 0.42^{\mathrm{b}}$ & $42 \pm 0.34^{\mathrm{b}}$ & $43.1 \pm 0.62^{\mathrm{b}}$ & $45 \pm 0.59^{\mathrm{b}}$ \\
\cline { 2 - 7 } & CCPS & $8.4 \pm 0.30^{\mathrm{a}}$ & $11.6 \pm 0.28^{\mathrm{a}}$ & $14.0 \pm 0.42^{\mathrm{a}}$ & $15.7 \pm 0.21^{\mathrm{a}}$ & $17.3 \pm 0.41^{\mathrm{a}}$ \\
\hline
\end{tabular}

As maximum compression stress increased, the proportion of elastic force in the maximum compression stress increased. Compared with CCS, the relaxation rate of CCPS after the same strain maintenance time was significantly lower, and the relaxation rate of CCPS after $30 \mathrm{~s}$ was $8.65 \%$, which was significantly different from that of CCS $(35.75 \%)$ ( $\mathrm{p}<0.05)$. The reason for this was that pressure maintenance after constant-speed compression could increase the compression displacement of straw, but elasticity of postcompression straw blocks was significantly enhanced, so the relaxation rate decreased. After $150 \mathrm{~s}$ of relaxation, the relaxation rates under CCS and CCPS varied within $42.6 \%$ 
to $45 \%$ and $17.3 \%$ to $18.7 \%$, respectively. Talebi et al. (2011) and Turner et al. (2018) found that the relaxation rates of dry grass, low-water original and crushed Miscanthus, and low-water original and low-water crushed Panicum virgatum were $27.4 \%$ to $53.7 \%$, $33.1 \%, 33.3 \%, 40.0 \%$, and $38.1 \%$, respectively.

The effects of strain maintenance time on the dimensional stability coefficient at the strain maintenance stage under CCS and CCPS are illustrated in Fig. 9. As the strain maintenance time was prolonged, the dimensional stability coefficient increased. At early stress relaxation, the increasing rate of the dimensional stability coefficient was large, and gradually decreased with the prolonging of time. The reason for this was that residual stress led to post-compression instability, and stress relaxation was fast at the early stage of stress relaxation. Compared with CCS, the dimensional stability coefficient of CCPS was always larger, which was because pressure maintenance during CCPS could increase the dimensional stability of post-compression straw blocks. At the maximum compression stresses of $60.8,120.8$, and $181.2 \mathrm{kPa}$, the increasing rates of CCS after $150 \mathrm{~s}$ of relaxation were $22.2 \%, 23.2 \%$, and $28.0 \%$ higher compared with CCPS, respectively. The reason for this was that residual stress relaxation was slow during relaxation, which led to postcompression instability.

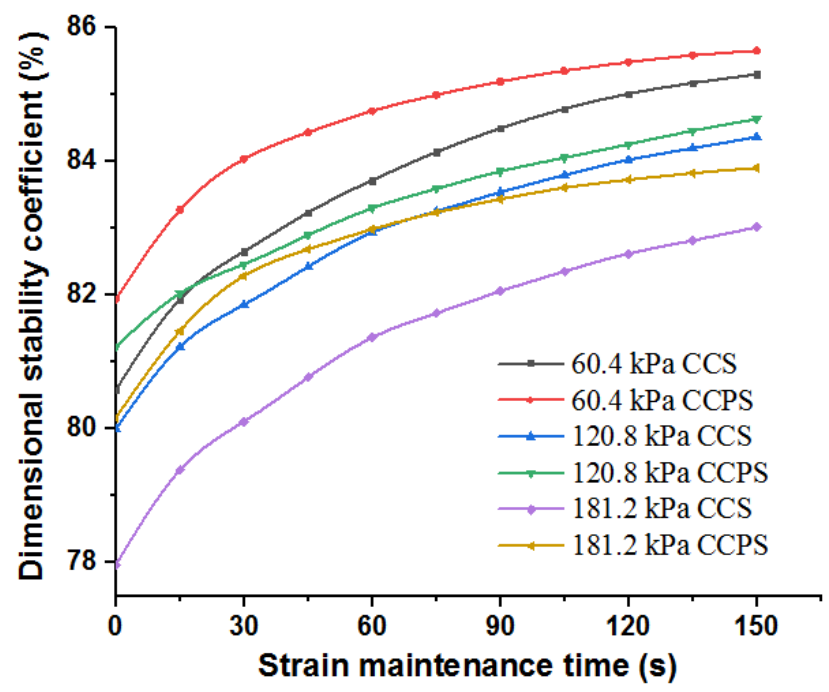

Fig. 9. Relationship between stability coefficient and strain maintenance time under two different compression methods (CCS and CCPS) for max compression stresses at 60.4, 120.8, and 181.2 $\mathrm{kPa}$

The above analyses implied that strain maintenance could decrease residual stress and rebounding force of post-compression straw blocks, and thereby prevent rebounding and increase the dimensional stability coefficient, which would enhance the compression effect of post-compression straw blocks. The strain maintenance of CCS compared with CCPS could more significantly enlarge the dimensional stability coefficient.

\section{Effects of Pressure Maintenance and Strain Maintenance on Post- compression Relaxation Density}

The pressure maintenance and strain maintenance differently affected the dimensional stability coefficient of post-compression chopped corn straw blocks, and thereby led to differences in the relaxation density. At the maximum compression stresses 
of $60.4,120.8$, and $181.2 \mathrm{kPa}$, the effects of different processes (CCS, CCP, and CCPS) on post-compression relaxation density are illustrated in Fig. 10. The post-compression relaxation density increased with the increase of compression stress. As reported, compression stress contributed to the compression of straw until its maximum reached the upper limit (Poddar et al. 2014; Said et al. 2015; Guo et al. 2016), after which the compressed density did not change any more (Adapa et al. 2009). The relaxation density of chopped corn straw maximized after CCPS, followed by CCS and CCP. The reason for this was that pressure maintenance was less effective than strain maintenance on the dimensional stability coefficient of post-compression straw blocks, but pressure maintenance could further compress the post-compression straw blocks and enlarge the compression displacement. Both jointly acted to enlarge the relaxation density of postcompression straw blocks after strain maintenance.
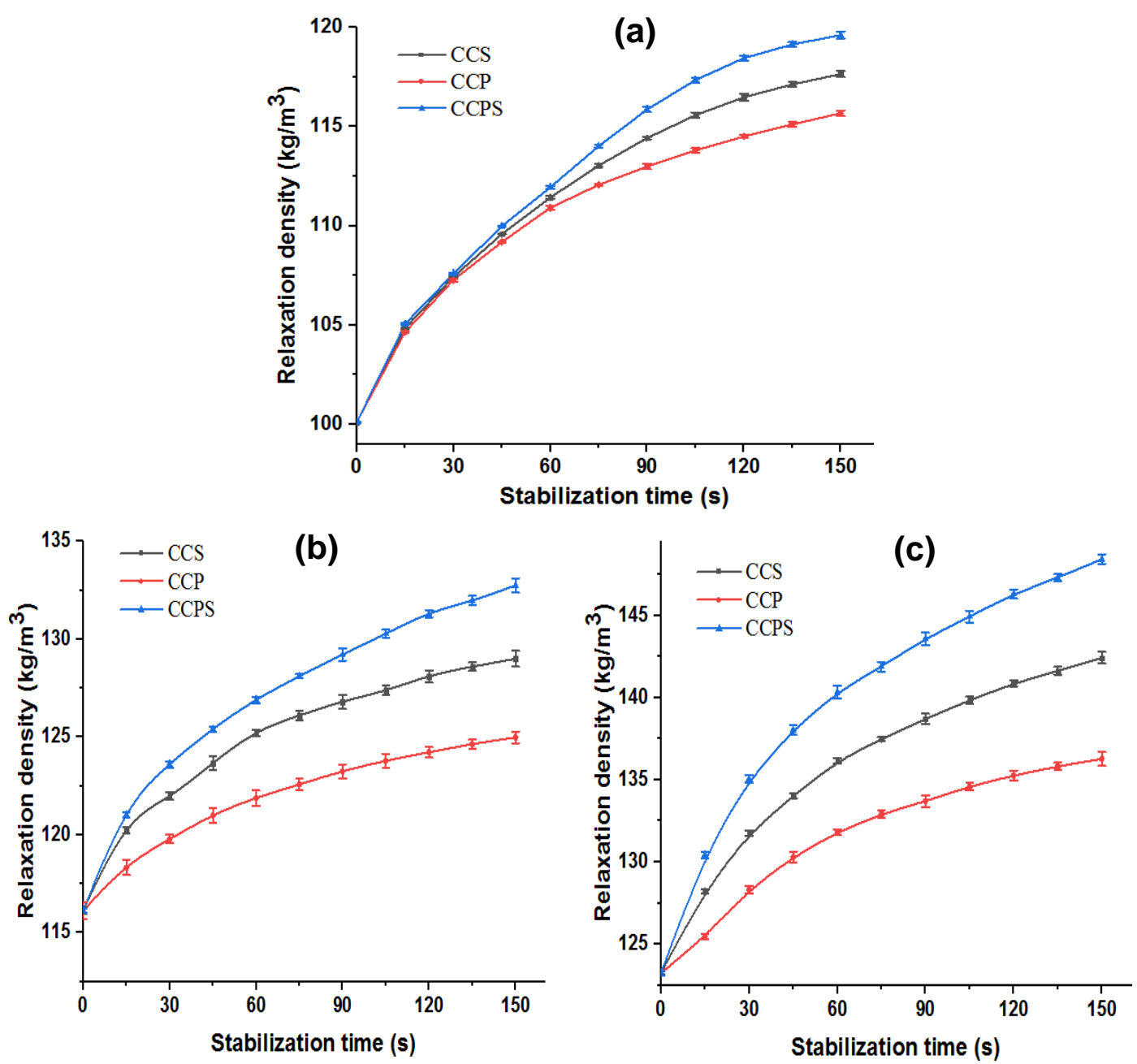

Fig. 10. Effects of different stability processes on compression relaxation density for max compression stresses: (a) $60.4 \mathrm{kPa}$, (b) $120.8 \mathrm{kPa}$, and (c) $181.2 \mathrm{kPa}$

As the pressure maintenance time and strain maintenance time were extended, relaxation density increased, but the increasing rate decreased, so the combination of pressure maintenance and strain maintenance could significantly increase the relaxation density of post-compression straw blocks. The compression process significantly affected 
post-compression relaxation density ( $\mathrm{p}<0.05)$, except for the case with the maximum compression stress of $60.4 \mathrm{kPa}$ and at early stage of stabilization. The reason for this was that at low compression stress and at early pressure maintenance stage, the compression displacement significantly increased, and thereby relaxation density of post-compression straw blocks was large. Compared with strain maintenance, relaxation density of straw blocks under the two processes was insignificant ( $p>0.05$ ). However, as the time was extended, the increment of compression displacement decreased, but strain maintenance significantly decreased the residual stress and post-compression rebounding and therefore, compared with pressure maintenance, the relaxation density of post-compression straw blocks was larger after strain maintenance.

\section{CONCLUSIONS}

Corn straw is loose and low-density, so compression can save the transport and storage costs. However, corn straw is also viscoelastic and it will rebound after compression, which will lower the compression effect. Pressure maintenance and strain maintenance are two procedures to prevent the post-compression straw blocks from rebounding. Thus, the stabilizing effects of two stabilization procedures were compared.

1. The authors compared the relationships of strain and stress with time during constantspeed compression (CC), constant-speed compression followed by strain maintenance (CCS), constant-speed compression followed by pressure maintenance (CCP), and constant-speed compression, pressure maintenance followed by strain maintenance (CCPS), and uncovered the reasons for them.

2. A Burgers model proved to be the most appropriate constitutive model for the pressure maintenance stage $\left(\mathrm{R}^{2}>0.990\right)$, and effects of pressure maintenance on strain and dimensional stability of post-compression straw blocks were investigated.

3. The effects of strain maintenance during CCS and CCPS on dimensional stability of post-compression straw blocks were compared. The Wiechert model B $\left(\mathrm{R}^{2}>0.990\right)$ proved to be the most suitable constitutive model at the strain maintenance stage. Additionally, effects of strain maintenance during CCS and CCPS on relaxation rate and dimensional stability coefficient of post-compression straw blocks were compared. The relaxation density of post-compression straw blocks was compared among the different stabilization processes.

4. The relaxation density of post-compression straw blocks was the largest after CCPS, followed by CCS and CCP. The compression process significantly affected postcompression relaxation density $(\mathrm{p}<0.05)$ except for the case with maximum compression stress of $60.4 \mathrm{kPa}$ and at early stage of stabilization.

\section{ACKNOWLEDGMENTS}

The authors gratefully acknowledge the financial support from the National Natural Science Foundation of China (Grant No.51705191), the National Key Research and Development Program of China (Grant No.2018YFD0701102), and the Science and Nature Foundation of Jilin Province (Grant No.20180101090JC). 


\section{REFERENCES CITED}

Adapa, P., Tabil, L., and Schoenau, G. (2009). "Compaction characteristics of barley, canola, oat and wheat straw," Biosyst. Eng. 104(3), 335-344. DOI: 10.1016/j.biosystemseng.2009.06.022

Adapa, P., Tabil, L., and Schoenau, G. (2011). "Grinding performance and physical properties of non-treated and steam-exploded barley, canola, oat and wheat straw," Biomass Bioenerg. 35(1), 549-561. DOI:10.1016/j.biombioe.2010.10.004

Aguayo, M. M., Sarin, S. C., Cundiff, J. S., Comer, K., and Clark, T. (2017). “A cornstover harvest scheduling problem arising in cellulosic ethanol production," BiomassBioenerg. 107, 102-112. DOI:10.1016/j.biombioe.2017.09.013

ASAE S358.2 (2008). "Moisture measurement -forages," American Society of Agricultural and Biological Engineers, St. Joseph, MI, USA.

Chen, L., Liao, N., Li, X., and Han, L. (2013). "Description of wheat straw relaxation behavior based on a fractional-order constitutive model," Agron. J. 105(1), 134-142. DOI:10.2134/agronj2012.0190

Chen, T.-Y., Meng, J., Xing, M.-J., Zhang, Q., Song, Y.-Q., Ren, W.-T., and Jiang, X. (2016). "Compaction behavior of biochar from corn stalk," J. Shenyang Agric. Univ. 47(6), 728-733.

Deng, J. L. (1986). "The main method of this characteristic grey system," Syst. Eng. Theor. Pract. 1, 60-65.

Fang, J., Zhang, Y., Yang, M., Wang, A., Wang, J., Liu, D., Gao, J., and Li, H. (2018). "Stress relaxation behavior and modeling of alfalfa during rotary compression," Trans. Chin. Soc. Agric. Eng. 34(16), 50-56. DOI:10.11975/j.issn.10026819.2018.16.007

Gong, Z. (2017). The Experimental Study on Rheology of Silage-Corn Stalk in the Mechanized Spiral Dense Forming Process, Ph.D. Dissertation, China Agricultural University, Beijing, China.

Guo, L., Wang, D., Tabil, L. G., and Wang, G. (2016). "Compression and relaxation properties of selected biomass for briquetting," Biosyst. Eng. 148, 101-110. DOI:10.1016/j.biosystemseng.2016.05.009

Herak, D., Kabutey, A., Choteborsky, R., Petru, M., and Sigalingginga, R. (2015). "Mathematical models describing the relaxation behaviour of Jatropha curcasL. bulk seeds under axial compression," Biosyst. Eng. 131, 77-83. DOI:

10.1016/j.biosystemseng.2015.01.004

Hou, J. (2013). Related Study on Mechanical Characteristic and Physicochemical Properties of Corn Straw, Master's Thesis, Northeast Agricultural University, Harbin, China.

Hu, J. J. (2008). Straw Pellet Fuel Cold Molding by Compression: Experimental Study and Numerical Simulation, Doctor's Thesis, Dalian University of Technology, Dalian, China.

Hu, J.-J., Lei, T.-Z., Xu, G.-Y., Shen, S.-Q., and Liu, J.-W. (2009). "Experimental study of stress relaxation in the process of cold molding with straw," BioResources 4(3), 1158-1167. DOI: $10.15376 /$ biores.4.3.1158-1167

Jha, S. K., Singh, A., and Kumar, A. (2008). "Physical characteristics of compressed cotton stalks," Biosyst. Eng. 99(2), 205-210. DOI:

10.1016/j.biosystemseng.2007.09.020 
Johnson, P., Cenkowski, S., and Paliwal, J. (2013). "Compaction and relaxation characteristics of single compacts produced from distiller's spent grain," J. Food Eng.116(2), 260-266. DOI: 10.1016/j.jfoodeng.2012.11.025

Kaliyan, N., and Morey, R. V. (2009). "Constitutive model for densification of corn stover and switchgrass," Biosyst. Eng. 104(1), 47-63. DOI: 10.1016/j.biosystemseng.2009.05.006

Kaliyan, N., and Morey, R. V. (2009). "Factors affecting strength and durability of densified biomass products," Biomass Bioenerg. 33(3), 337-359. DOI: 10.1016/j.biombioe.2008.08.005

Li, R., Geng, A., Zhao, H., Bao, W., and Fan, X. (2012). "Rheologic behavior of chopped corn stalks during rotary compression," Trans. Chin. Soc. Agric. Eng. 28(18), 30-35. DOI:10.3969/j.issn.1002-6819.2012.18.005

Li, W. (2011). Study on Creep Properties of Maize Straw Rubbed During Open Compression, Master's Thesis, Inner Mongolia Agricultural University, Huhhot, China.

Li, Z., Yan, L., Gao, Y.-H., Wang, H.-Q., and Wang, P. (2019). "Research status on biomass compression molding process model," Sci. Technol. Eng. 19(12), 1-7.

Liu, Y., Liu, D., Gao, W., Gong, Y., Wang, R., Bai, X., and Qin, J. (2017). "The experiment of critical forming condition of corn stalk silk compression," J. Agric. Mech. Res. 2017(4), 168-172. DOI:10.13427/j.cnki.njyi.2017.04.033

Ma, F., Bai, X., Liu, D., Gong, Y., and Chen, Z. (2017). "The typical biomass coldpressing constitutive model and influence factors analysis of viscous-elasticplasticity," ActaEnerg. Sol. Sin. 38(1), 98-105.

Ma, L., and Daemen, J. J. K. (2006). "An experimental study on creep of welded tuff," Int. J. Rock Mech. Min. Sci. 43(2), 282-291. DOI:10.1016/j.ijrmms.2005.07.002

Ma, Y., Xuan, C., Wu, P., Yang, J., Su, H., and Zhang, Y. (2016). "Experiment on stress relaxation of corn stover during compression with assisted vibration," Trans. Chin. Soc. Agric. Eng. 32(19), 88-94. DOI:10.11975/j.issn.1002-6819.2016.19.012

Mani, S., Tabil, L. G., and Sokhansanj, S. (2006). "Effects of compressive force, particle size and moisture content on mechanical properties of biomass pellets from grasses," BiomassBioenerg. 30(7), 648-654. DOI:10.1016/j.biombioe.2005.01.004

Mani, S., Tabil, L. G., and Sokhansanj, S. (2004). "Evaluation of compaction equations applied to four biomass species," Can. Biosyst. Eng. 46, 355-361.

Miao, Z., Phillips, J. W., Grift, T. E., and Mathanker, S. K. (2015). "Measurement of mechanical compressive properties and densification energy requirement of Miscanthus $\times$ giganteus and switchgrass," BioEnergy Res. 8(1), 152-164. DOI: 10.1007/s12155-014-9495-8

Mostafa, M. E., Hu, S., Wang, Y., Su, S., Hu, X., Elsayed, S. A., and Xiang, J. (2019). "The significance of pelletization operating conditions: An analysis of physical and mechanical characteristics as well as energy consumption of biomass pellets," Renew. Sust. Energ. Rev.105, 332-348. DOI:10.1016/j.rser.2019.01.053

Mohsenin, N., and Zaske, J. (1976). "Stress relaxation and energy requirements in compaction of unconsolidated materials," J. Agric.Eng. Res. 21(2), 193-205. DOI: 10.1016/0021-8634(76)90074-3

Myhan, R., and Jachimczyk, E. (2015). "Rheological properties of a straw layer," Rheol. Acta 54(1), 19-27. DOI: 10.1007/s00397-014-0811-1 
Nona, K. D., Lenaerts, B., Kayacan, E., and Saeys, W. (2014). "Bulk compression characteristics of straw and hay," Biosyst. Eng.118, 194-202. DOI: 10.1016/j.biosystemseng.2013.12.005

Poddar, S., Kamruzzaman, M., Sujan, S. M. A., Hossain, M., Jamal, M. S., Gafur, M. A., and Khanam, M. (2014). "Effect of compression pressure on lignocellulosic biomass pellet to improve fuel properties: Higher heating value," Fuel 131, 43-48. DOI: 10.1016/j.fuel.2014.04.061

Said, N., Abdel Daiem, M. M., García-Maraver, A., and Zamorano, M. (2015). "Influence of densification parameters on quality properties of rice straw pellets," Fuel Process. Technol.138, 56-64. DOI:10.1016/j.fuproc.2015.05.011

Shaw, M. D. (2008). Feedstock and Process Variables Influencing Biomass Densification, Master's Thesis, University of Saskatchewan, Saskatoon, Canada.

Song, X., Zhang, M., Pei, Z. J., and Wang, D. (2015). "Ultrasonic vibration-assisted (UVA) pelleting of wheat straw: A constitutive model for pellet density," Ultrasonics 60 , 117-125. DOI:10.1016/j.ultras.2015.03.002

Talebi, S., Tabil, L., Opoku, A., and Shaw, M. (2011). "Compression and relaxation properties of timothy hay," Int. J. Agric. Biol. Eng. 4(3), 69-78. DOI: 10.3965/j.issn.1934-6344.2011.03.069-078

Theerarattananoon, K., Xu, F., Wilson, J., Ballard, R., Mckinney, L., Staggenborg, S., Vadlani, P., Pei, Z. J., and Wang, D. (2011). "Physical properties of pellets made from sorghum stalk, corn stover, wheat straw, and big bluestem," Ind. Crop. Prod. 33(2),325-332. DOI:10.1016/j.indcrop.2010.11.014

Tumuluru, J. S., Tabil, L. G., Song, Y., Iroba, K. L., and Meda, V. (2015). "Impact of process conditions on the density and durability of wheat, oat, canola, and barley straw briquettes," BioEnergyRes. 8(1), 388-401. DOI:10.1007/s12155-014-9527-4

Turner, A. P., Sama, M. P., Bryson, L. S., and Montross, M. D. (2018). "Effect of stem crushing on the uniaxial bulk compression behaviour of switchgrass and miscanthus," Biosyst. Eng.175, 52-62. DOI:10.1016/j.biosystemseng.2018.08.007

Wang, C. (2007). "Stress relaxation time of hay and its application," Trans. Chin. Soc. Agric. Mach. 38(1), 65-67.

Wang, C., Yang, M., Gao, H., Li, L., and Li, X. (1997). "Study on stress-relaxation of hay during baling under high density," Trans. Chin. Soc. Agric. Eng. 13(3), 48-52.

Wang, H., Wang, F., Sun, R., Gao, C., Wang, Y., Sun, N., Wang, L., and Bi, Y. (2016). "Policies and regulations of crop straw utilization of foreign countries and its experience and inspiration for China," Trans. Chin. Soc. Agric. Eng. 32(16), 216-222. DOI:10.11975/j.issn.1002-6819.2016.16.030

Wongsiriamnuay, T., and Tippayawong, N. (2015). "Effect of densification parameters on the properties of maize residue pellets," Biosyst. Eng. 139, 111-120. DOI: 10.1016/j.biosystemseng.2015.08.009

$\mathrm{Xu}, \mathrm{Y} ., \mathrm{Wu}, \mathrm{Q}$., Lei, Y., and Yao, F. (2010). "Creep behavior of bagasse fiber reinforced polymer composites,” Bioresource Technol. 101(9), 3280-3286.

DOI:10.1016/j.biortech.2009.12.072

Yang, M. (2010). Rheology of Agricultural Materials, China Agriculture Press, Beijing, China.

Yang, M., Li, X., and Yang, H. (1996). "Research on the hay compression process," Trans. Chin. Soc. Agric. Eng. 12(1), 60-64. 
Yin, D., Wu, M., and Li, D. (2016). "Microstructure of ball milling corn stalk and creep behavior of corn starch-based films," Trans. Chin. Soc. Agric. Mach. 47(S1), 297304. DOI: 10.6041/j.issn.1000-1298.2016.S0.046

Yuan, X., Li, P., Wang, H., Wang, X., Cheng, X., and Cui, Z. (2011). "Enhancing the anaerobic digestion of corn stalks using composite microbial pretreatment," Korean J. Microbiol. Biotechnol. 21(7), 746-752. DOI: 10.4014/jmb.1011.11026

Yu, H., Shi, G., Liu, H., Deng, X., Cui, X., Pan, G., and Xi, W. (2019). "A nonlinear viscoelastic stress relaxation model of rock based on fractional calculus," J. Basic Sci. Eng. 27(1), 199-209. DOI:10.16058/j.issn.1005-0930.2019.01.017

Zhang, L., Yang, Z., Zhang, Q., and Guo, H. (2016). "Tensile properties of maize stalk rind," BioResources 11(3), 6151-6161. DOI:10.15376/biores.11.3.6151-6161

Zhang, X., Peng, W., Han, L., Xiao, W., and Liu, X. (2018). "Effects of different pretreatments on compression molding of wheat straw and mechanism analysis," Bioresource Technol. 251, 210-217. DOI:10.1016/j.biortech.2017.12.015

Article submitted: November 23, 2019; Peer review completed: January 25; Revised version received and accepted: March 18; 2020; Published: April 1, 2020.

DOI: 10.15376/biores.15.2.3717-3736 